\title{
The efficacy of intraosseous blood and ringer lactate in a rabbit model of hemorrhagic hypovolemia
}

\author{
Tanzer Korkmaz ${ }^{1, *}$, S. Hakan Atalgın ${ }^{2}$, H. Ali Kilicgun ${ }^{3}$, Onursal Bugra ${ }^{4}$, \\ Nurettin Kahramansoy
}

${ }^{1}$ Abant İzzet Baysal University, Faculty of Medicine,_Department of Emergency

${ }^{2}$ Abant İzzet Baysal University Faculty of Medicine, Veterinarian

${ }^{3}$ Abant İzzet Baysal Universty Faculty of medicine, Department of Thoracic Surgery

${ }^{4}$ Abant İzzet Baysal University Faculty of Medicine, Department of Cardiovascular Surgery

${ }^{5}$ Abant İzzet Baysal University Faculty of Medicine, General Surgery

\section{Email address:}

tanzerkorkmaz@gmail.com (T. Korkmaz),sukruhakan@hotmail.com (S. Hakan Atalgın), kilicgun@gmail.com (H. Ali Kilicgun), onursalbugra@gmail.com (O. Bugra),nurkahramansoy@yahoo.com (N. Kahramansoy)

\section{To cite this article}

Tanzer Korkmaz, S. Hakan Atalgın, H. Ali Kilicgun, Onursal Bugra, Nurettin Kahramansoy. The Efficacy of Intraosseous Blood and Ringer Lactate in a Rabbit Model of Hemorrhagic Hypovolemia . Clinical Medicine Research. Vol. 2, No. 2, 2013, pp. 18-23.

doi: 10.11648/j.cmr.20130202.13

\begin{abstract}
Purpose: In this study, flow rates of intraosseously (IO) or intravenously (IV) administered fluids (blood or Ringer lactate) and their effects on vital signs were examined in a rabbit model of hypovolemia. Methods: Underanesthesia, $20 \mathrm{~mL}$ of blood was removed from each of the 36 New Zealand-type rabbits. Ten minutes later, each group of nine rabbits received one of four fluids by gravity flow from a height of $100 \mathrm{~cm}$ : blood via IO, Ringer Laktat (RL) via IO, blood via IV, or RL via IV. IO fluids were given in the proximal tibia through a $15 \mathrm{~g}$ needle placed with an EZ-IO instrument; IV fluids were given through a $22 \mathrm{~g}$ catheter in the femoral vein. Vital signs were monitored for four hours after the infusion ended. Results: Flow rates were blood IO $2.6 \mathrm{~mL} / \mathrm{min}$, RL IO $3.4 \mathrm{~mL} / \mathrm{min}$, blood IV $3.2 \mathrm{~mL} / \mathrm{min}$, and RL IV $11.8 \mathrm{~mL} / \mathrm{min}$. Ten minutes after fluid administration ended, in the RL via IO group, heart rate was significantly slower than preinfusion; in the blood via IO group, body temperature was significantly lower than preinfusion, and in the blood via IO group, StO2 saturation was higher than preinfusion. Postinfusion respiratory rates within groups were not significantly different than preinfusion rates. Vital sign changes between groups were not significantly different. Conclusion: Fluids given by gravity feed through an IO needle were effective in treating hypovolemia in this rabbit model, but the flow of RL and blood were significantly slower through the $15 \mathrm{~g}$ IO needle than the $22 \mathrm{~g} \mathrm{IV}$ catheter.
\end{abstract}

Keywords: Intraosseous Infusion, Flow Rate, Blood Infusion

\section{Introduction}

Although treatment of trauma patients has advanced considerably in recent years, trauma still ranks first among causes of death in the first three decades of life [1]. For hypovolemic shock due to massive traumatic hemorrhage, Advanced Trauma Life Support (ATLS) guidelines recommend rapid fluid and blood product replacement prior to and during repair of the underlying injury [1,2]. Beginning fluid resuscitation in a timely manner may reduce mortality and morbidity in patients with hemorrhagic shock [3]. The site chosen for fluid administration should be safe, reliable, and allow for quick access. The intravenous (IV) route is usually used, but peripheral venous cannulation during the pre-hospital phase is difficult in many patients, causing delays in transport and/or treatment. With improvements in technology, intraosseous (IO) access is now preferred by many pre-hospital care providers because of the speed and ease with which a needle may be placed [4-6]. In lifethreatening cases such as major trauma, cardiopulmonary arrest, sepsis, shock, and major burns, IO infusion is recommended by both the International Liaison Committee on Resuscitation (ILCOR) and the American Heart Association (AHA) guidelines [7,8]. IO access is considered a safe, fast, effective alternative route of fluid and drug administration [5,7-9]. Although its clinical use began after the Tocantis' rabbit experiments in 1941, interest was lost after the development of improved IV equipment and methods. 
A resurgence of interest has occurred in the last decade for patients in whom peripheral vascular cannulation could not be obtained $[8,10,11]$.

The goal of this study was to compare the flow rates of blood and Ringer lactate (RL) through peripheral IV catheters versus IO catheters in an animal model of significant hemorrhage (without hemodynamic instability) and to compare the effects of the infusions on hemodynamic parameters.

\section{Methods}

This experimental study was conducted with the approval of our institutional Animal Studies Ethics Committee. Thirty-six healthy, 3-4 kg female white New Zealand rabbits were housed in a climate-controlled facility and given ad libitum access to food and water. In a temperaturecontrolled room, anesthesia was induced by IM injection of a combination of $5-10 \mathrm{mg} / \mathrm{kg}$ xylazine $\mathrm{HCl}$ (Rompun ${ }^{\circledR}$, Bayer Healthcare AG, Toronto, Canada) and 30-50 mg/kg ketamine $\mathrm{HCl}$ (Ketalar $\AA$, Parke Davis-Eczacıbaşı, Istanbul, Turkey). Respiratory rate, heart rate, rectal temperature, and oxygen saturation were continuously monitored with a model BSM-2301K monitor (Nihon Kohden Corp., Tokyo, Japan) and YCOM rectal temperature probe (Kınataş Medist Medical, Istanbul, Turkey). Ten minutes after anesthetics were given, after femoral tissues were incised, a 22-gauge Nova-cath catheter $(25 \mathrm{~mm}$ long, Medipro Inc., Istanbul, Turkey) was placed in the femoral vein of each animal and $20 \mathrm{~mL}$ of blood (approximately $10 \%$ of the total blood volume) was withdrawn. The blood was withdrawn using an injector washed with heparin and put into a blood bag containing sodium citrate and phosphate, to be used for auto transfusion (Groups 1 and 3). Ten minutes after blood was withdrawn, fluid administration (RL or blood) began. Animals were randomly assigned into one of four groups (9 animals in each group) to receive $20 \mathrm{~mL}$ of blood via IO (Group 1), $20 \mathrm{~mL}$ of RL via IO (Group 2), $20 \mathrm{~mL}$ of blood via IV (Group 3), or $20 \mathrm{~mL}$ of RL via IV (Group 4). In Group $3(n=9)$ and Group $4(n=9)$, the femoral catheter was then left in place for subsequent fluid administration, but in the IO groups it was removed. Group $1(n=9)$ and Group 2 $(n=9)$ rabbits had a 15 gauge IO needle $(15 \mathrm{~mm}$ long, Vidacare Corp, San Antonio, USA) placed in the medial aspect of their proximal tibia with an EZ-IO ${ }^{\circ}$ device (Vidacare Corp, San Antonio, USA). Bone marrow aspiration was performed to verify placement of the IO needle, which was then washed with $0.5 \mathrm{~mL}$ of sterile saline [10]. The distance between the bag containing blood or RL and the IO or IV catheter was $100 \mathrm{~cm} \mathrm{[3],} \mathrm{and} \mathrm{fluids} \mathrm{were} \mathrm{run} \mathrm{in} \mathrm{under} \mathrm{grav-}$ ity only at room temperature.

After fluid administration ended, the catheters were removed, wounds were closed with 3-0 prolene sutures, and vital signs were monitored for an additional four hours.

\section{Data Analysis}

Data for analysis included flow rates of the fluids $(\mathrm{mL} / \mathrm{min})$ and vital signs recorded 5 minutes after anesthetics were given, 10 minutes after withdrawal of $20 \mathrm{~mL}$ of blood, and 10 minutes after completion of the blood or RL infusion. All descriptive data are presented as median \pm SEM. Flow rates were compared and analyzed using the Kruksal-Wallis and post-hoc Mann-Whitney U tests. Vital sign data at the various time points within groups were compared with the Friedman and Mann-Whitney U tests. One-way ANOVA and Bonferroni post-hoc tests were used for comparisons between groups. Data analysis was performed using SPSS 17.0 for Windows ${ }^{\circledR}$ (SPSS Inc., Chicago, USA). A p value less than 0.05 was considered statistically significant.

\section{Results}

The flow rates of the fluids through the IV or IO catheters were blood via IO $2.6 \mathrm{~mL} / \mathrm{min}$ (range 1.3-15.0 $\mathrm{mL} / \mathrm{min}$ ), RL via IO $3.4 \mathrm{~mL} / \mathrm{min}$ (range $1.4-20.0 \mathrm{~mL} / \mathrm{min}$ ), blood IV $3.2 \mathrm{~mL} / \mathrm{min}$ (range 3.6-10.0 $\mathrm{mL} / \mathrm{min}$ ), and $\mathrm{RL} \mathrm{IV}$ $11.8 \mathrm{~mL} / \mathrm{min}$ (range: $8.0-24.1 \mathrm{~mL} / \mathrm{min}$ ). Flow in the Group 1 animals (blood via IO) was significantly slower than the flow rates in the other groups $(\mathrm{p}=0.001)$. The flow rate in Group 1 (blood via IO) was slower than the flow rate in Group 3 (blood via IV, $\mathrm{p}=0.007$ ). The flow rate of $\mathrm{RL}$ via IV was significantly faster than $R L$ via IO $(p=0.005)$ (Figure).

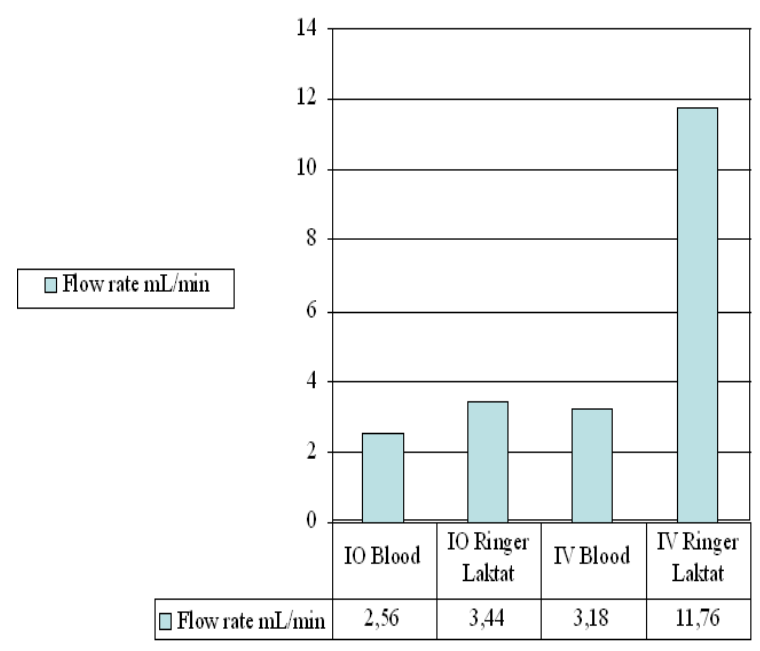

Figure 1. Comparison of test groups for fluid flow rates

Throughout the study, in all groups, respiratory rate and oxygen saturation increased, and heart rate and temperature decreased (Table 1). Respiratory rates did not change significantly throughout the study in Groups 1 and 2 (blood and RL via $\mathrm{IO})$. Ten minutes after fluid administration ended, heart rate was significantly slower than preinfusion in the RL via IO group; in the blood via IO group, body temperature was significantly lower than preinfusion, and in the blood via IO group, $\mathrm{StO} 2$ saturation was higher than pre-infusion (Table 2). Post-infusion respiratory rates with- 
in groups were not significantly than pre-infusion rates. were not significantly different.

Pre- and post-infusion vital signs changes between groups

Table 1. Vital signs (median and 95\% confidence intervals) in rabbits at baseline, 10 minutes post-hemorrhage, and 10 minutes after completion of fluid administration.

\begin{tabular}{|c|c|c|c|c|c|}
\hline & & $\begin{array}{l}\text { Group } 1 \\
\text { (blood via IO }\end{array}$ & $\begin{array}{l}\text { Group } 2 \\
\text { (RL via IO) }\end{array}$ & $\begin{array}{l}\text { Group } 3 \\
\text { (blood via IV) }\end{array}$ & $\begin{array}{l}\text { Group } 4 \\
\text { (RL via IV) }\end{array}$ \\
\hline \multirow{3}{*}{ Breaths/min } & Baseline & $64(57-71)$ & $60(54-61)$ & $60(57-64)$ & $60(57-61)$ \\
\hline & Post-hemorrhage & $60(52-68)$ & $60(53-64)$ & $60(57-67)$ & $60(59-63)$ \\
\hline & Post-fluid & $66(58-76)$ & $64(57-71)$ & $64(62-68)$ & 64 (64-69) \\
\hline \multirow{3}{*}{$\begin{array}{l}\text { Heart rate } \\
\text { (Beats/min) }\end{array}$} & Baseline & $172(151-188)$ & $183(158-202)$ & $190(164-200)$ & 190(163-199) \\
\hline & Post-hemorrhage & $190(165-208)$ & $168(153-188)$ & $170(131-192)$ & $160(128-188)$ \\
\hline & Post-fluid & $167(153-182)$ & $167(139-184)$ & $168(153-180)$ & $150(146-165)$ \\
\hline \multirow{3}{*}{ Temp. $\left({ }^{\circ} \mathrm{C}\right)$} & Baseline & $39(38-39)$ & $39(38-39)$ & $39(38-39)$ & $39(38-39)$ \\
\hline & Post-hemorrhage & $38(37-38)$ & $37(37-38)$ & $37(36-37)$ & $38(37-38)$ \\
\hline & Post-fluid & $38(37-38)$ & $38(37-38)$ & $37(36-38)$ & $38(37-38)$ \\
\hline \multirow{3}{*}{$\mathrm{StO} 2(\%)$} & Baseline & $86(81-92)$ & $85(82-91)$ & $92(87-94)$ & $92(88-93)$ \\
\hline & Post-hemorrhage & 87 (8-94) & 94 (87-98) & $92(86-96)$ & $96(93-96)$ \\
\hline & Post-fluid & $94(88-95)$ & 94 (93-97) & 94 (88-97) & 95 (92-97) \\
\hline
\end{tabular}

IO: Intraosseous. RL: Ringer lactate .StO2: Oxygen saturation

Table 2. $P$ values of data comparisons of vital signs in rabbits at baseline, 10 minutes post-hemorrhage, and 10 minutes after completion of fluid administration.

\begin{tabular}{|c|c|c|c|c|}
\hline & $\begin{array}{l}\text { Group 1 } \\
\text { (Blood via IO) }\end{array}$ & $\begin{array}{l}\text { Group } 2 \\
\text { (RL via IO) }\end{array}$ & $\begin{array}{l}\text { Group 3 } \\
\text { (Blood via IV) }\end{array}$ & $\begin{array}{l}\text { Group } 4 \\
\text { (RL via IV) }\end{array}$ \\
\hline \multicolumn{5}{|l|}{ Breaths/minute } \\
\hline Baseline / Post-hemorrhage & 0.175 & 0.340 & 0.892 & 0.034 \\
\hline Baseline / Post- fluid & 0.261 & 0.106 & 0.168 & 0.007 \\
\hline Post-hemorrhage / Post- fluid & 0.084 & 0.232 & 0.111 & 0.006 \\
\hline \multicolumn{5}{|l|}{ Pulse (beats/minute) } \\
\hline Baseline / Post-hemorrhage & 0.038 & 0.028 & 0.173 & 0.108 \\
\hline Baseline / Post- fluid & 0.859 & 0.015 & 0.138 & 0.011 \\
\hline Post-hemorrhage / Post- fluid & 0.051 & 0.155 & 0.372 & 0.108 \\
\hline \multicolumn{5}{|l|}{ Temperature } \\
\hline Baseline / Post-hemorrhage & 0.008 & 0.008 & 0.008 & 0.007 \\
\hline Baseline / Post- fluid & 0.008 & 0.779 & 0.008 & 0.007 \\
\hline Post-hemorrhage / Post- fluid & 0.235 & 0.050 & 0.778 & 0.916 \\
\hline \multicolumn{5}{|l|}{$\mathrm{StO} 2$} \\
\hline Baseline / Post-hemorrhage & 0.040 & 0.050 & 0.497 & 0.026 \\
\hline Baseline / Post- fluid & 0.021 & 0.017 & 0.154 & 0.057 \\
\hline Post-hemorrhage / Post- fluid & 0.106 & 0.168 & 0.248 & 0.498 \\
\hline
\end{tabular}

IO: Intraosseous .RL: Ringer lactate .StO2: Oxygen saturation

\section{Discussion}

IO access with one of several devices is often used after unsuccessful peripheral IV placement in pre-hospital or inhospital situations. Liedal et al., used the spring-loaded Bone Injection Gun (BIG, Waismed Ltd., New York, USA) and $\mathrm{EZ}-\mathrm{IO} \otimes$ drill in their study of parenteral access after 2 minutes of attempts to start a peripheral IV. They found a non-significant advantage in speed with the EZ-IO device (1.8 min vs. $2.2 \mathrm{~min}$. with the BIG device) and successful first attempt (EZ-IO: 90\%, BIG: 80\%) [4]. Other studies report similar success rates $(96 \%, 96.5 \%, 97 \%)$ with the EZ-IO $[5,9,12]$. Success rates of central venous canulation and IO access were compared in 10 trauma patients on whom peripheral vascular access could not be achieved after three attempts for a maximum of two minutes; first attempt success rate was $90 \%$ for IO access and $60 \%$ for 
central venous access. Mean procedure time was significantly shorter for IO cannulation ( $2.3 \mathrm{~min}$ ) compared to central line placement $(9.9 \mathrm{~min})$ [13] . We preferred to use EZ - IO device in our study due to its easy application.

The administration of fluid to maintain and restore intravascular volume from hypovolemia increases tissue perfusion and helps prevent vasoconstriction and regional hypoperfusion [14]. Hence, in cases of massive traumatic blood loss, obtaining rapid vascular access to begin fluid resuscitation may directly affect mortality and morbidity. Flow rates of fluids depend on the characteristics of the fluid, type of catheter, and administration method [3]. The infusion fluid flow rate is proportional to catheter diameter and inversely proportional to catheter length [2,3]. Large-bore peripheral intravenous (IV) catheters have traditionally been the first choice for obtaining venous access [15]. The viscosity of $\mathrm{RL}$ at room temperature is $0.9 \mathrm{cps}$, while that of blood at $37^{\circ} \mathrm{C}$ is $2.2-4.5 \mathrm{cps}[3,16]$. As expected, in our study, blood flowed slower than RL in both IO and IV groups. Chen IY et al. reported similar findings in their study of crystalloids (RL, 7.5\% saline, water) and colloids

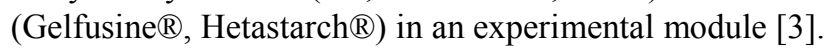

A study of IO access after failed peripheral IV placement in adult emergency department patients examined IO infusion rates of fluids, which were under $300 \mathrm{mmHg}$ pressure and $80 \mathrm{~cm}$ higher than the catheter [10]. Yasar et al. performed a study under the same conditions but without applying pressure to the fluid bag [17]. Both studies used $15 \mathrm{~g}$ IO catheters as we did; in their studies, the flow rates of RL under pressure were $30-40 \mathrm{~mL} / \mathrm{min}$ under pressure and 5 $10 \mathrm{~mL} / \mathrm{min}$ by gravity and the flow rate of normal saline was $7-10 \mathrm{~mL} / \mathrm{min}$ by gravity $[10,17]$.

In a study of manually pressurized fluid infusions in pigs, the blood infusion rates were $21 \mathrm{~mL} / \mathrm{min}$ through a 15 $\mathrm{g}$ IO needle and $35 \mathrm{~mL} / \mathrm{min}$ through a $16 \mathrm{~g}$ peripheral IV catheter [18]. The blood infusion rates in our study were only $2.6 \mathrm{~mL} / \mathrm{min}$ for IO and $3.2 \mathrm{~mL} / \mathrm{min}$ for IV. Considering difficulties in giving fluids under pressure in the prehospital arena or ED, the fluids in our study were given by gravity flow only, without the use of pressure. The lower flow rates of fluid and blood we found compared to those in other studies are probably related to our not using pressure when infusing the fluids.

Because of the significant circulation in bone marrow and quick transfer of drugs to the systemic circulation, IO infusion is considered an effective and fast (usually obtained in 1-2 minutes) method for administering fluids or medications after failure of IV access in cardiopulmonary resuscitation scenarios [10, 19]. For treatment of ventricular fibrillation_in a pig model, Mader et al. found that epinephrine was more quickly administered via IO (0.84 minutes) than by peripheral IV (6.68 $\mathrm{min})$; the $20 \mathrm{~min}$ survival rate was also higher in their IO group (21 of 26 survivors vs 16 of 27 survivors) [20]. In a study of the IO infusion of normal saline versus a hydroxycobalamin solution, Borron et al. found no significant differences in heart rates in a goat model [21].

Voelckel et al. , created hemorrhagic shock and cardiac arrest by withdrawing $35 \%$ of the blood volume of pigs and then administering IO vasopressin or adrenaline [22]. In their adrenaline group, the flow rate through the bone marrow was lower in their animals receiving epinephrine. Because hemorrhagic shock can lead to unpredictable flow in the bone marrow, they advised giving fluids through IO needles under pressure. As expected, they also found a rapid increase of the heart rate after IO epinephrine was given [22].

In acute hemorrhage, the body attempts to increase blood flow to vital organs through a variety of compensatory responses. In addition to the decrease in vagal tone caused by stimulation of baroreceptors, heart rate and cardiac output increase [14]. In our study, we withdrew $10-15 \%$ of the test animals' total blood volume in order to create hypovolemia, but to a degree in which the vital signs remained normal. The lowered body temperature observed throughout the procedure might have been due to hypovolemia or the effect of anesthesia [23, 24]. The downtrend of body temperatures was statistically significant only in Group 1 (blood via IO), perhaps because of the longer length of time it took for the infusion to be completed. In their swine model of hemorrhagic hypovolemia, Plewa et al., did not find any changes in heart rate when autotransfused blood was given via IO needle [18]. In the literature, we found no data regarding changes in respiration rate, body temperature or oxygen saturation after IO infusions.

While a UK survey, performed in 1996, found IO equipment in only $7 \%$ of emergency departments (ED), a 2009 survey in Denmark found that $95 \%$ of ED personnel knew about IO lines, but only $48 \%$ had received training [25-26]. In this latter study, an average of five IO lines were placed per month per ED surveyed. Voigt et al., concluded in their review of IO access in 2012 that IO lines were underused and that large, randomized studies of their use as an alternative parenteral access line should be performed [27]. We also feel that although many studies have found IO infusion to be an effective method for rapid medication administration, its effectiveness in cases of failed peripheral vascular access needs to be studied more thoroughly.

\section{Limitations}

The catheters used in our study were of different size; we used the largest size (22 gauge) catheter that would fit in the femoral vein of our rabbits, and the only size (15 gauge) IO needle available on the market for the EZ-IO ${ }^{\circledR}$ drill. The diameters of the catheters thus contributed to some degree to the varying flow rates we observed. The amount of blood $(20 \mathrm{~mL})$ removed from each rabbit was not standardized according to its weight. The proportion removed thus varied slightly, and this may have affected the changes in vital signs in individual rabbits. We did not compare 
vital signs at both early and late phases of hypovolemia thus may have missed significant changes at these time points.

\section{Conclusion}

Fluids given through an IO needle were effective in treating hypovolemia in this rabbit model of gravity infusion into the tibia of rabbits, as determined by maintenance of vital signs within the normal range. IO infusion rates of both blood and RL were significantly slower through the 15 gauge IO needle than the 22 gauge IV catheter. Fluids that must be given rapidly should be given via IV catheter, if one can be placed. The IO route should be used for rapid fluid administration only if a large-bore peripheral IV cannot be placed within the first few minutes of care.

\section{References}

[1] Mizushima Y, Tohira H, Mizobata Y, Matsuoka T, Yokota J. Fluid resuscitation of trauma patients: how fast is the optimal rate. Am J Emerg Med 2005;23:833-7.

[2] Li SF, Cole M, Forest R, Chilstrom M, Reinersman E, Jones MP, Zinzuwadia S, King S, Yadav K. Are 2 smaller intravenous catheters as good as 1 larger intravenous catheter. American Journal of Emergency Medicine 2010;28:724-7.

[3] Chen IY, Huang YC, Lin WH. Flow-rate measurements and models for colloid and crystalloid flows in central and peripheral venous line infusion systems. IEEE Trans Biomed Eng 2002;49:1632-8.

[4] Leidel BA, Kirchhoff C, Braunstein V, Bogner V, Biberthaler P, Kanz KG. Comparison of two intraosseous access devices in adult patients under resuscitation in the emergency department: A prospective, randomized study. Resuscitation 2010;81:994-9.

[5] Ong M.EH, Ngo A.SY, Wijaya R. An Observational, Prospective Study to Determine the Ease of Vascular Access in Adults Using a Novel Intraosseous Access Device. Ann Acad Med Singapore 2009;38:121-4.

[6] Luck RP, Haines C, Mull CC. Intraosseous Access. The Journal of Emergency Medicine 2010;39:468-75.

[7] Neumar RW, Otto CW, Link MS, Kronick SL, Shuster M, Callaway CW, Kudenchuk PJ, Ornato JP, McNally B, Silvers SM, Passman RS, White RD, Hess EP, Tang W, Davis D, Sinz E, Morrison LJ. Adult Advanced Cardiovascular Life Support: 2010 American Heart Association Guidelines for Cardiopulmonary Resuscitation and Emergency Cardiovascular Care. Circulation 2010;122:729-67.

[8] Hartholt KA, Lieshout EM, Thies WC, Patka P, Schipper I.B Intraosseous Devices: A Randomized Controlled Trial Comparing Three Intraosseous Devices. Prehospital Emergency Care 2010;14:6-13.

[9] Gazin N, Auger H, Jabre P, Jaulin C, Lecarpentier E, Bertrand C, Margenet A, Combes X. Efficacy and safety of the EZ-IO ${ }^{\text {TM }}$ intraosseous device: Out-of-hospital implementation of a management algorithm for difficult vascular access. Resuscitation 2011;8:126-9.
[10] Waisman M, Waisman D. Bone Marrow Infusion in Adults. The Journal of Trauma 1997;42:288-93.

[11] Wright C, Mahoney P, Hodgetts T, R.Russell. Fluid Resuscitation: A Defence Medical Service Delphi Study Into Current Practice. JR Army Med Corps 2009;155:99-104.

[12] Shavit I, Hoffmann Y, Galbraith R, Waisman Y. Comparison of two mechanical intraosseous infusion devices: A pilot, randomized crossover trial. Resuscitation 2009;80:1029-33.

[13] Leidel BA, Kirchhoff C, Bogner V, Stegmaier J, Mutschler W, Kanz KG, Braunstein V. Is the intraosseous access route fast and efficacious compared to conventional central venous catheterization in adult patients under resuscitation in the emergency department? A prospective observational pilot study. Patient Saf Surg 2009;3:24.

[14] Ozsaraç M, Karcioglu O, Topaçoglu H, Topacoglu H, Ayrik C. Hemorajik şokta tanı, fizyopatoloji ve genel yaklaşım. Akademik Acil Tıp Dergisi 2004;3:23-29.

[15] Mikrogianakis A, Kam A, Silver S, Bakanisi B, Henao O, Okrainec A, Azzie G. Telesimulation: An Innovative and Effective Tool for Teaching Novel Intraosseous Insertion Techniques in Developing Countries. Academic Emergency Medicine 2011;18:420-7.

[16] Gordon D, Lowe O. Rheological infuences on thrombosis. Bailliere's Clinical Haematology 1999;12:435-49.

[17] Yaşar M, Dündaröz R, Sızlan A, Baykal B, Denli M, Özışık $\mathrm{T}$. Intraosseous Infusion Using the Bone Injection Gun in a Natural Mass Disaster. Medical Journal of Süleyman Demirel University 1999;6:29-33.

[18] Pl Yaşar M, Dündaröz R, Sizlan A, Baykal B, Denli M, Özışı T. Hematologic Safety of Intraosseous Blood Transfusion in a Swine Model of Pediatric Hemorrhagic Hypovolemia. Acad Emerg Med. 1995;2:799-809.

[19] Buck ML, Wiggins BS, Sesler JM. Intraosseous drug administration in children and adults during cardiopulmonary resuscitation. Ann Pharmacother. 2007;41:1679-86.

[20] Mader TJ, Kellogg AR, Walterscheid JK, Lodding CC, Sherman LD. A randomized comparison of cardiocerebral and cardiopulmonary resuscitation using a swine model of prolonged ventricular fibrillation. Resuscitation. 2010;81:596-602.

[21] Borron SW, Arias JC, Bauer CR, Sanchez M, Fernández M, Jung I. Hemodynamics after intraosseous administration of hydroxocobalamin or normal saline in a goat model. Am J Emerg Med. 2009;27:1065-71.

[22] Voelckel WG, Lurie KG, McKnite S, Zielinski T, Lindstrom P, Peterson C, Wenzel V, Lindner KH. Comparison of epinephrine with vasopressin on bone marrow blood flow in an animal model of hypovolemic shock and subsequent cardiac arrest. Crit Care Med. 2001;29:1587-92.

[23] Bergstein JM, Slakey DP, Wallace JR, Gottlieb M. Traumatic hypothermia is related to hypotension, not resuscitation. Ann Emerg Med. 1996;27:39-42.

[24] Sessler DI. Temperature monitoring and perioperative thermoregulation. Anesthesiology. 2008;109:318-38.

[25] Lavis M, Vaghela A, Tozer C. Adult intraosseous infusion in accident and emergency departments in the UK. J Accid 
Emerg Med. 2000;17:29-32.

[26] Molin R, Hallas P, Brabrand M, Schmidt TA. Current use of intraosseous infusion in Danish emergency departments: a cross-sectional study. Scand J Trauma Resusc Emerg Med. 2010;18:37.
[27] Voigt J, Waltzman M, Lottenberg L. Intraosseous vascular access for in-hospital emergency use: a systematic clinical review of the literature and analysis. Pediatr Emerg Care. 2012;28:185-99. 